\title{
Acute optic neuritis in multiple sclerosis
}

\author{
Brian Garrett BSc, Adam A. Dmytriw MD MSc, Charles Maxner MD
}

See also www.cmaj.ca/lookup/doi/10.1503/cmaj.141389
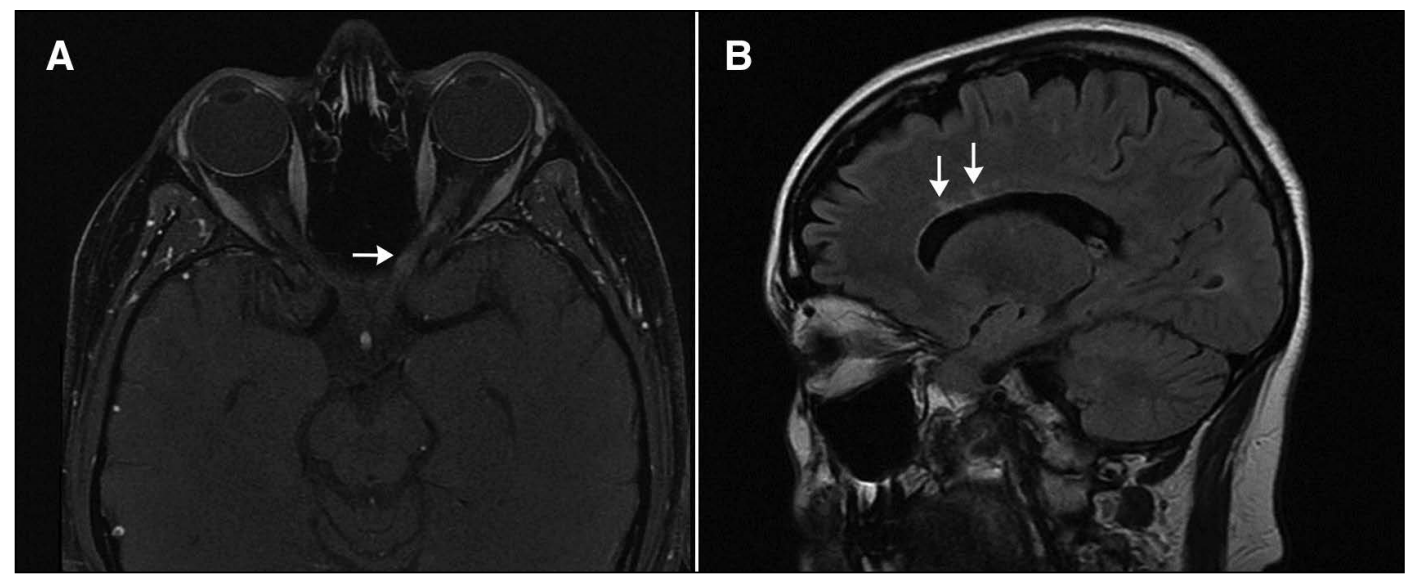

Figure 1: (A) Gadolinium-enhanced, fat-suppressed, $T_{1}$-weighted magnetic resonance (MR) scan showing mild thickening and abnormal enhancement (arrow) throughout the left optic nerve in a 37-year-old woman with visual loss in her left eye. (B) Sagittal $T_{2}$-weighted FLAIR (fluid attenuated inversion recovery) MR scan, in which cerebrospinal fluid appears dark and areas of brain inflammation or demyelination appear high in signal, as shown in periventricular white matter (arrows).

A 37-year-old woman presented to the emergency department with a two-week history of blurred central vision in her left eye. She had 20/20 vision in her right eye but could count fingers only at $1.2 \mathrm{~m}$ using her left eye. Confrontation visual field testing identified a central defect in her left eye. An Ishihara test indicated impaired colour vision in the affected eye (red desaturation), and the swinging flashlight test showed a relative afferent pupillary defect. The patient's ocular motility was full bilaterally, and fundus examination showed normal-appearing optic discs and maculae. The remainder of the neurologic examination was unremarkable. Magnetic resonance (MR) scans showed thickening and abnormal enhancement throughout the left optic nerve (Figure 1A) and lesions of high signal intensity perpendicular to the ventricles (Figure 1B), which suggested demyelinating plaques. We suspected multiple sclerosis (MS); subsequent work-up and follow-up confirmed the diagnosis. The patient declined steroid therapy after the potential risks and benefits were explained. She recovered most of her vision within two weeks.

Acute optic neuritis is an isolated inflammatory optic neuropathy secondary to demyelination and is considered one of the clinically isolated syndromes that may represent an initial manifestation of MS. The five-year incidence of MS is 30\% in patients who have acute optic neuritis as a first presentation, with a median time to diagnosis of three years. ${ }^{1}$ The risk of MS is lower if the baseline MRI is normal. ${ }^{2}$

Spontaneous recovery of visual function occurs in $80 \%$ of patients within two to three weeks. Intravenous or oral corticosteroid therapy accelerates recovery but does not influence the ultimate visual outcome. ${ }^{3}$ Use of oral prednisolone alone increases the risk of recurrent optic neuritis. ${ }^{2}$ Oral prednisone treatment is not recommended, and intravenous use of steroids (e.g., methylprednisolone) represents the best currently available option for patients electing to hasten recovery of their vision.

\section{References}

1. Atkins EJ, Biousse V, Newman J. The natural history of optic neuritis. Rev Neurol Dis 2006;3:45-56.

2. Torres-Torres R, Sanchez-Dalmau B. Treatment of acute optic neuritis and vision complaints in multiple sclerosis. Curr Treat Options Neurol 2015;17:328.

3. Hoorbakht H, Bagherkashi F. Optic neuritis, its differential diagnosis and management. Open Ophthalmol J 2012;6:65-72.
Competing interests: None declared.

This article has been peer reviewed.

The authors have obtained patient consent.

Affiliations: Division

of Neurology, and

Department of

Ophthalmology and Visual

Sciences (Garrett, Maxner),

Dalhousie University,

Halifax, NS; Department of

Medical Imaging

(Dmytriw), University of

Toronto, Toronto, Ont

Correspondence to:

Adam Dmytriw,

dmytriwa@smh.ca

CMAJ 2016. DOI:10.1503

/cmaj.150811 